\title{
Educação, Formação e (Auto)Formação de Mulheres
}

Apresentação

O Grupo de Pesquisa Interinstitucional "Educação de Mulheres nos Séculos XIX e XX”, organizador do Dossiê - Educação, Formação e (Auto)Formação de Mulheres especialmente dedicou essa edição da Revista Diálogo Educacional aos estudos e pesquisas sobre os lugares de enunciação da educação e, igualmente, da formação de mulheres que representam seus coletivos de classe e que foram as protagonistas de significativas mudanças sociais.

O Dossiê publicado é composto de dezesseis artigos de pesquisadoras e pesquisadores de instituições universitárias de todas as regiões brasileiras e de Portugal. Parte dos artigos é derivada dos estudos desse Grupo de Pesquisa Interinstitucional, mediante o Projeto $A$ educação de mulheres ao longo dos séculos XIX $e$ $X X$, financiado pelo Edital do Universal (2018) do Conselho Nacional de Desenvolvimento Científico e Tecnológico (CNPq).

No primeiro artigo intitulado "As especialidades convenientes à educação de mulheres no Brasil (séculos XIX e XX)", Marta Maria de Araújo e Cristina Coimbra Vieira refletem sobre os ofícios convenientes à educação de mulheres e sobre os fundamentos social-pedagógicos da educação feminina, referentes aos séculos XIX e XX no Brasil.

No artigo seguinte, "Ensinamentos e contos: Maria Amália Vaz de Carvalho e sua estratégia para a educação da mulher”, Maria Celi Chaves Vasconcelos analisa as obras Mulheres e Crianças: notas sobre educação e Contos e Phantasias, acerca da educação feminina, de autoria da poetisa e escritora portuguesa Maria Amália Vaz de Carvalho, publicadas no ano de 1880. Em um plano mais específico, aborda a concepção da autora sobre a educação doméstica de meninas, realizada pelas próprias mães ou por mestras contratadas. 
No estudo "Naíde Regueira Teodósio: médica, professora e pesquisadora em tempos autoritários", Raylane Andreza Dias Navarro Barreto e Carliane Maria do Carmo Lins da Natividade analisam a relação formação-atuação profissionalenfrentamento a regimes autoritários da médica, professora, pesquisadora pernambucana e militante do Partido Comunista Brasileiro, Naíde Regueira Teodósio, no período de 1915 a 2005.

Em "Cartas, diários e cadernos de uma preceptora: a Condessa de Barral através de seus escritos", Ana Cristina Borges López Monteiro Francisco apresenta e interpreta parte dos itinerários pedagógicos adotados pela Condessa de Barral, enquanto preceptora principal das herdeiras do Trono do Brasil, Isabel e Leopoldina, filhas de D. Pedro II, de 1856 a 1864.

No trabalho "Formação educacional e redes de sociabilidade intelectual de Eudésia Vieira na Paraíba (Século XX)", Amanda Sousa Galvíncio e Jean Carlo de Carvalho Costa procuram entender como ocorreram o processo de formação educacional e os deslocamentos nos espaços de sociabilidade intelectual de Eudésia Vieira nas primeiras décadas do século XX, além da narrativa individual, para tecerem paralelos com outras trajetórias femininas do mesmo período, identificando-a de modo geracional.

No artigo "Entre lar e Igreja: A Educação de mulheres e as Congregações Religiosas na Amazônia Paraense (1900-1927)", Tayana Helena Cunha Silva e Laura Maria Silva Araújo Alves analisaram as ações e práticas educativas das Congregações Filhas de Sant'Ana e Irmãs de Santa Doroteia, nas primeiras décadas do século XX.

No estudo “A escrita educacional feminina de Maria Lacerda de Moura (19181919)", Paula Cristina David Guimarães examina a escrita educacional feminina da professora de escola normal do interior de Minas Gerais, Maria Lacerda de Moura, nos livros Educação (1918) e Renovação (1919), identificando as diferentes relações de poder que permeavam a atuação da mulher no contexto educacional e social.

No texto "A formação de professoras na Escola Normal Nossa Senhora da Piedade (1919 a 1925)", Martha Raíssa Iane Santana da Silva e Larissa Pinca Sarro Gomes interrogam, especificamente, a respeito dos saberes ofertados na Escola Normal Nossa Senhora da Piedade, da cidade de Ilhéus (Bahia), de inspiração 
francesa, assim como discutem as contribuições dessa instituição e de sua interiorização à propagação do ensino primário.

No artigo "A invenção da inversão: ciência, educação e lesbianidade", Marlon Silveira da Silva, Marcio Caetano e Maria da Conceição Silva Soares verificam os discursos científicos sobre a homossexualidade feminina, produzidos entre as décadas de 1920 e 1950, particularmente as representações presentes nesses discursos, que contribuíram na invenção daquilo que foi assimilado como a invertida sexual e/ou homossexual feminina.

No trabalho "A feminização do magistério: o lugar da mulher como professora no Triângulo Mineiro e Alto Paranaíba", Michelle Castro Lima analisa a formação de professoras da Escola Normal e do Magistério, além da relação entre a feminização e o exercício do magistério no Triângulo Mineiro e no Alto Paranaíba de 1946 a 1979.

No artigo "Mulheres na universidade: a presença feminina no movimento estudantil paranaense (1964-85)", Luana Regina Borges e Alexandre Felipe Fiuza abordam a participação feminina no Movimento Estudantil Universitário paranaense durante a ditadura civil-militar brasileira (1964-1985), tendo como foco de análise o processo histórico da inserção feminina na educação formal e no ensino superior ao longo dos séculos XIX e XX.

Em "Encontros e percursos de professoras militantes: Hildésia Medeiros e Dodora Mota", Lia Ciomar Macedo de Faria e Thaís Rodrigues Martins evidenciam os trajetos de vida de Hildésia Medeiros e Maria das Dores Pereira Mota, perscrutando seus processos de formação inicial, o encontro entre ambas e sua repercussão em seus caminhos, para assim compreenderem como se forjaram suas concepções e atuação em prol da educação pública.

No artigo "Formação e educação da mulher e o caderno de Economia Doméstica (Dourados, Mato Grosso - 1972)", Inês Velter Marques e Alessandra Cristina Furtado analisam o ensino de Economia Doméstica no Colégio Estadual Presidente Vargas da cidade de Dourados, tendo, como fonte principal, um caderno de uma ex-aluna do Curso Ginasial do ano de 1972.

No artigo "Enfrentamentos e aprendizados: a insurgência feminina no Acampamento Zé Maria do Tomé, Chapada do Apodi-CE”, Sandra Maria Gadelha de Carvalho, Mila Nayane da Silva e Lia Pinheiro Barbosa apresentam o processo de 
aprendizagem repercutido na vida das camponesas, enfatizando a práxis de resistência contra o patriarcado emergida no contexto da luta pela terra, coordenada pelo Movimento dos Trabalhadores Rurais Sem Terra. Analisam, portanto, os aprendizados ocorridos nas reverberações políticas e subjetivas da inserção das mulheres no MST.

No estudo "Casamento cigano: tradição ou crime? Processos educativos de constituição de mulheres ciganas", Gláucia Siqueira Marcondes e Anderson Ferrari problematizam os modos pelos quais três mulheres ciganas vão se constituindo enquanto mulheres dessa cultura, demonstrando como os aparatos de verdade e de poder, sobre infância e pedofilia, interferem no modo como compreendemos o casamento cigano.

No último artigo do Dossiê “'Outros' coletivos femininos: Lutas e Resistências que formam mulheres quilombolas na Amazônia”, Ellen Rodrigues da Silva Miranda e Doriedson do Socorro Rodrigues evidenciam que os coletivos femininos das mulheres quilombolas estão inseridos no campo do debate de gênero, raça, patriarcado e classe. Por sua vez, os seus modos, suas lutas e resistências constituem-se em "outras" formas de lutas ao capital e fazem parte dos processos formativos das classes sociais, revelando-se como lutas sociais distintas de "outros" coletivos femininos.

Mulheres professoras, educadoras, preceptoras, escritoras, militantes políticas, camponesas, ciganas, quilombolas e mulheres de outros coletivos femininos, em diferentes tempos e lugares foram iluminadas pelos dezesseis artigos reunidos no presente Dossiê, que, inevitavelmente, revelaram as peculiaridades apreensíveis da educação, da formação e da (auto)formação por ângulos particulares, múltiplos e de classe, mas também os protagonismos que elas tiveram nas lutas sociais.

A segunda parte deste número é composta por oito artigos provenientes de demanda contínua, o primeiro dos quais é "O protagonismo da mulher no Suplemento Feminino do jornal O Estado de S. Paulo”, de autoria das pesquisadoras Gizeli Fermino Coelho, Raquel dos Santos Quadros e Maria Cristina Gomes Machado. Com o objetivo de analisar o modo como o Suplemento Feminino do jornal O Estado de São Paulo propagava ideais que levavam as mulheres paulistas a contribuírem com a articulação do Golpe Militar de 1964, foram estudados textos e propagandas publicados entre os anos de 1960 e 1964. Verificou-se que o discurso veiculado pelo Suplemento era duplamente 
ideológico, dando voz às mulheres nas decisões políticas, mas convencendo-as de que o seu lugar se restringia ao lar, no qual atuaria como protetora do lar, da família e da pátria.

Ana Paula Gestoso de Souza e Aline Maria de Medeiros Rodrigues Reali, no artigo "Mentoras de professoras iniciantes: a construção de uma base de conhecimentos", trazem os resultados de uma pesquisa-intervenção na qual foram estudados as contribuições e os limites de um programa híbrido de mentoria para o desenvolvimento profissional de professores experientes e de professores iniciantes. As categorias que compõem a base de conhecimento para a mentoria foram obtidas por meio da análise de narrativas escritas pelas mentoras sobre sua experiência com as professoras iniciantes. Constatou-se, também, a importância da mentoria para auxiliar as professoras iniciantes a lidarem com as tensões vividas e na busca de soluções.

$\mathrm{Na}$ sequência, tem-se o artigo "Incursões sobre a estruturação da disciplina de Libras nos cursos de formação de professores”, em que Karina Ávila Pereira e Mayara Bataglin Raugust problematizam as práticas discursivas que se constituem como verdades, legitimando o ensino de Língua Brasileira de Sinais - Libras - como segunda língua no ensino superior. Os resultados apontaram para a necessidade de uma reordenação da disciplina, no sentido de que desenvolva habilidades de expressão e de compreensão mas, também, produza um profissional consciente das singularidades linguísticas de seus futuros alunos.

Adiante, tem-se o artigo de Dayse Kelly Barreiros de Oliveira, Fabiana Margarita Gomes Lagar e Kátia Augusta Curado Pinheiro Cordeiro da Silva, intitulado "Sociedade civil e sociedade política na formação stricto sensu de professores da educação básica: correlações de força”. O objetivo da pesquisa, com base no pensamento de Antonio Gramsci, foi buscar compreender a relação e as contradições existentes entre sociedade civil e sociedade política, no que se refere ao entendimento da pós-graduação stricto sensu como possibilidade de formação continuada de professores da educação básica. Observou-se a existência de conflitos entre os dois polos da superestrutura, demonstrando não haver unidade entre sociedade civil e sociedade política quanto à formação docente na educação básica, o que acaba por gerar políticas públicas fragmentadas e descontínuas.

Em "Fluência tecnológico-pedagógica na docência universitária", os autores Daniele da Rocha Schneider, Rogério Tubias Schraiber e Elena Maria Mallmann 
analisam a fluência tecnológico-pedagógica de professores em um curso de formação continuada denominado "REA: Educação para o Futuro", ofertado pela Small Open Online Course a professores e servidores da rede pública da educação básica do Rio Grande do Sul. A pesquisa possibilitou verificar que o professor fluente avança para níveis de reflexão, análise e produção de conhecimento mais profundos em relação às áreas de planejamento, organização de metodologias e estratégias didáticas, avaliação e interações entre os participantes.

O artigo de autoria de Yohana Taise Hoffmann e David Antonio da Costa, "Circulação de ideias em eventos da História da educação matemática" tem como objetivo apresentar socio-historicamente a circulação de ideias a partir de eventos e revistas científicas do campo da História da educação matemática. Da análise, constatou-se que os espaços que a História da educação matemática vem ocupando contribuem para o processo de reconhecimento, legitimação, socialização e circulação de ideias do respectivo campo.

"Corpo privado da liberdade e o esporte: perspectivas educacionais", dos pesquisadores Laudeth Alves dos Reis e Wagner Wey Moreira, tem por objetivo analisar como os integrantes de uma instituição socioeducativa de internação compreendem o corpo e as possibilidades educativas da prática esportiva. Os discursos dos adolescentes e dos agentes socioeducativos foram ora divergentes, ora convergentes, evidenciando a necessidade de se realizarem mais estudos sobre a temática.

Como oitavo artigo da segunda parte deste número, Maria Lourdes Gisi e Isabel Voirol-Rubido apresentam "Politiques de L'enseignement Supérieur au Brésil et en Suisse" [Políticas para a educação superior no Brasil e na Suíça], com o objetivo de identificar semelhanças decorrentes da implementação das políticas de educação superior nos dois países, a partir de 1990. A pesquisa, de natureza documental, indicou existirem semelhanças na organização da educação superior, em especial no que se refere à diversificação institucional e às exigências de avaliação institucional. Contudo, no que se refere à mobilidade estudantil e ao financiamento da educação superior, há diferenças significativas entre os países estudados.

Por último, não poderíamos encerrar a apresentação deste número sem consignar que, com esta $67^{\text {a }}$ edição, a Revista Diálogo Educacional completa 20 anos 
de publicação ininterrupta, com foco na pesquisa em formação de professores e pensamento educacional brasileiro.

O momento é especial, para o Programa de Pós-Graduação em Educação da Escola de Educação e Humanidades da Pontifícia Universidade Católica do Paraná, por representar a consolidação de um trabalho inteiramente dedicado à educação do nosso país.

Agradecemos aos autores que nos confiaram suas pesquisas; aos colegas de universidades brasileiras e estrangeiras que participaram da organização dos dossiês; aos avaliadores, que incansavelmente colaboraram, fazendo a leitura criteriosa dos textos e oferecendo sugestões para a melhoria da qualidade da revista; aos colaboradores da PUCPRESS, parceiros incondicionais que atuaram com especial diligência na edição dos números; e aos nossos leitores, razão de nosso trabalho, que nos prestigiam e estimulam a continuar.

A todos e a todas, desejamos uma excelente leitura!

As editoras

\author{
MARTA MARIA DE ARAÚJOa \\ Maria Celi Chaves Vasconcelos ${ }^{b}$ \\ Raylane ANDREZa Dias NaVARRo BARRETO ${ }^{c}$ \\ CRISTINA C. VIEIRA ${ }^{d}$ \\ Alboni Marisa DUdeque PIANOVSKI VIEIRA ${ }^{\mathrm{e}}$
}

\footnotetext{
a Professora da Universidade Federal do Rio Grande do Norte (UFRN). Doutora em Fundamentos da Educação e Didática (USP), e-mail: martaujo@uol.com.br

${ }^{b}$ Professora da Universidade do Estado do Rio de Janeiro (UERJ). Doutora em Educação (PUC-Rio), e-mail: maria2.celi@gmail.com

'Professora da Universidade Federal de Pernambuco (UFPE). Doutora em Educação (UFRN), e-mail: raylane.navarro@ufpe.br

d Professora Associada da Faculdade de Psicologia e de Ciências da Educação da Universidade de Coimbra - Portugal. Doutora em Ciências da Educação - Psicologia da Educação, e-mail: vieira@fpce.uc.pt

e Professora da Pontifícia Universidade Católica do Paraná (PUCPR). Doutora em Educação (PUCPR), e-mail: alboni@alboni.com
} 